\title{
GRADUATE STUDENT INTERNSHIPS AS A PATHWAY TO THE PROFESSION OF EDUCATIONAL DEVELOPMENT
}

Kathryn E. Linder, Suffolk University

Stephanie V. Rohdieck, Alan Kalish, Teresa A. Johnson, Kathryn M. Plank, Laurie A. Maynell, The Ohio State University

Educational developers can help create a cadre of well-prepared new professionals by mentoring them during graduate study. Through an educational development intern position, we created a mentorship opportunity for graduate students interested in the field of educational development as a career opportunity. Teaching center staff, participating graduate student interns, and the field of educational development benefited from the model.

Although graduate students are often mentored within the field of educational development through opportunities such as graduate assistantships in teaching and learning centers, more extensive and structured formal training experiences for graduate students are rare. In this article, we argue that through an educational development intern position, teaching centers can create a mentorship opportunity for graduate students who are interested in the field of educational development as a career opportunity. While all graduate student positions in teaching centers may create allies or new professionals for the field serendipitously (Gosling, McDonald, \& Stockley, 2007; Meizlish \& Wright, 2009), the internship position we describe is meant to intentionally train new professionals who want to pursue a career within educational development. 


\section{The Literature on Mentoring New Developers}

In the past decade, educational development scholars have begun to study their own training and pathways into the field (Chism, 2007; Gosling et al., 2007; McDonald \& Stockley, 2008, 2010; Meizlish \& Wright, 2009; Stefani, 1999). With the exception of Meizlish and Wright (2009), these studies do not include thoughts on training and mentoring graduate students into careers as educational developers.

While scholars point to the importance of having multiple pathways into the field (Gosling et al., 2007; Stefani, 1999), new educational developers have expressed their desire for mentorship before and as they are entering the field (Jensen, 2002). Despite training programs from organizations such as the Professional and Organizational Development (POD) Network, which offers annual one-week and one-day workshops for new professionals, scholars have found that developers are entering the field with little experience. Indeed, Chism (2007) found that developers often receive "on-the-job" training without any prior preparation (p. 1).

The literature on acculturation to the academic profession suggests that formal, sequential, serial, and affirming forms of socialization tend to lead to more successful outcomes for those seeking to join the profession (Tierney \& Rhoads, 1994). Recent research has pointed to the value of similarly structured activities for professionals entering the field of educational development to gain both content knowledge and hands-on experience (Chism, 2007; McDonald, 2010). Scholars in the field have also begun to argue for the importance of "growing our own" (Meizlish \& Wright, 2009, p. 386), encouraging teaching centers to take on the responsibility of training and mentoring new professionals into the field.

Mentorship initiatives such as the POD internship grant program have illustrated the success of intentional pipeline support in which opportunities are created for graduate students and faculty members to be trained as educational developers. Ouellet and Stanley (2004) found not only that the POD internship grant program benefited teaching centers that participated, but also that the program "does appear to serve as a catalyst for engaging interns further in faculty and instructional development careers" (pp. 215-216). For centers at institutions with graduate student populations, the opportunity exists to mentor new professionals from the beginning of their academic careers.

With no specific higher education program devoted to training future educational developers (Gosling et al., 2007; Knapper, 2010; McDonald \& Stockley, 2008), graduate students interested in the profession must often pursue whatever activities are available to them through their campus 
teaching center or other campus organizations that support teaching and learning. These opportunities may include volunteer facilitator positions for workshops or events or paid positions as administrative staff or graduate assistants within a teaching center. Because "the educational developer has become a recognized professional role which has moved from the fringes to the mainstream of higher education" (Gosling et al., 2007, p. 4), we believe that centers should consider offering graduate students structured mentorship opportunities to learn more about educational development as a career choice within the larger academy.

\section{A Doctoral Internship Program at The Ohio State University}

The University Center for the Advancement of Teaching (UCAT) at The Ohio State University developed a two-year doctoral internship position in 2007. The center is a moderately sized development unit, employing five permanent full-time consulting staff, a program coordinator, an office manager, a visiting consultant, and several graduate and undergraduate students. Through conversations and interactions with senior graduate students who had previously worked with our office, the staff identified potential candidates for the internship who were interested in exploring educational development in higher education as a career and invited them to apply for the position. Candidates were then interviewed by staff and selected based on their career path plans, their level of teaching experience, their indication of a genuine interest in the field, and their time to degree. One intern was selected for the first cycle (2007-2009), one for the second cycle (2009-2011), and one for the third cycle (2011-2113). All of our interns to date have been senior graduate students who have graduated on schedule; our most recent intern graduated before completing the internship after accepting a job in educational development.

The UCAT doctoral intern position consists of a twenty-hour-per-week paid graduate administrative associateship and independent study. The intern is expected to assume both research and administrative tasks, while also assisting professional staff in the teaching support mission of the office. Although the intern has many similar job tasks to our other graduate associates (GAs), such as consultation, workshop facilitation, and research responsibilities, the intern assumes a greater leadership role in a wider range of center activities.

Each intern first meets with and interviews each UCAT staff member to learn about various aspects of UCAT's work. The intern also learns 
about each staff member's educational development responsibilities and philosophy and entry into the field. Throughout the two-year term, the intern continues to meet monthly with UCAT's director to discuss the progress of the mentorship and to ask questions that have arisen about educational development during this training. At each meeting, the intern produces a monthly reflection paper on her or his experiences and receives feedback on her or his training. After the first year, the intern is given the opportunity to pursue a writing project of choice: the first-year intern transitioned her monthly reflection papers into writing an article, and the second-year intern transitioned her papers into drafts of a philosophy of practice for use on the job market. In each of six areas of doctoral internship training and mentorship-events, consulting, learning communities, teaching, teaching center administration, and general professionalization activities-our interns receive direct feedback from staff on performance, client feedback in the form of event assessment surveys and an annual client survey on consultation services, and anonymous client feedback solicited for an annual performance review.

\section{Events}

The academic year at UCAT begins with our annual university-wide teaching orientation for more than five hundred new graduate teaching associates. Both interns have helped UCAT staff redesign orientation curriculum, facilitate sessions at the orientation, train graduate student facilitators, and work with various orientation committees.

Throughout the year, our center also offers both campuswide and departmental workshops that are designed and presented by individual consulting staff. Since this is an integral component of teaching center services, both interns have been involved in all stages of workshop planning. As an introduction to the workshop experience, each intern went through a training process that included observing a workshop facilitated by a staff member, cocreating content and agendas, cofacilitating the workshops, and ultimately independently facilitating a workshop with feedback from staff observers and campus participants.

The hiring of our second intern in summer 2009 coincided with our university's beginning the process of converting from a quarter-based to a semester-based system. To facilitate this large-scale transformation, our teaching center created a fifteen-hour institute on course design and another on curriculum design. The intern thus had an opportunity to participate in the design and implementation of a long-term event series from its earliest planning stages through its assessment and revision. 
The UCAT staff believed it was important to provide the interns with a full and realistic experience of the skills consultants need to successfully design and facilitate campuswide events and an understanding of the complex nature of such events in terms of public relations, content, goals, logistics, and staffing. Our choice to involve the interns with large-scale events from start to finish allowed staff to contextualize each event in terms of both the center's role within the university and the purpose of the event within the larger mission of our teaching center.

\section{Consulting}

Individual teaching consultation is a significant component of educational development and one of the core services that our center provides. In order for our interns to receive a foundational understanding of the intricacies of the consultation experience as well as the complexity of the consultant-client relationship, they go through a shadowing and debriefing process that is required of all new staff and graduate student consultants.

The training procedure is similar to that described for events. The three-step process follows the developmental path of new practitioners as they build knowledge and confidence before working with faculty and graduate student clients independently. First, the intern shadows several staff members on a number of consultations, sitting in on the meetings and taking notes on the interactions without interacting with the client. The staff members and intern then debrief the consultation, discussing questions the intern has for the staff members about choices made in the interaction, the rationale for the choices made, and ways that the intern may have done things differently had he or she been the consultant.

The second step in the training process is co-consultation: the intern is brought into a consultation that a staff member usually leads. The intern eventually becomes an equal participant in the interaction by asking clarifying questions, answering client questions, and offering recommendations. This intermediate step allows the intern to gain confidence interacting with clients as part of a team.

The final step in the training is for the intern to conduct consultations independently but with staff members present. The intern has complete autonomy as to the direction of the consultation, and the staff member in the room takes notes on what the intern has done well and ideas for improvement. The additional benefit of this step is that the intern can bring the staff member into the conversation or ask questions if 
necessary. Intern progression through these three steps depends on intern skills as well as the consultation needs of the center. After the intern completes all three steps to staff satisfaction, the intern can then consult with clients independently.

In addition to shadowing, the intern attends monthly codevelopment meetings where we discuss client cases, training progression, and relevant literature, as well as engage in case scenarios and role-play activities designed to strengthen the intern's consultation skills. The interns have found that these codevelopment meetings have the benefit of building community with other GAs in the office who are frequently working on different projects from the intern. Building community around consultation experience allows all participants in the codevelopment sessions to contribute their thoughts and ideas for tough cases (for example, clients who come to the center without a specific reason or graduate students with very low teaching evaluation scores).

The training procedure for interns is very similar to that of new consultants and GAs, although there are several important differences. First, rather than working with one staff member, interns are asked to shadow and co-consult with multiple staff members so they are exposed to a wide variety of models. Also, whereas the procedure we have outlined for consultants and GAs typically occurs over a full year, interns follow an accelerated schedule. Finally, the debriefing portion is usually more in-depth for interns than for other graduate students. Interns may also be given tougher consults than their GA peers and are asked to co-consult with staff members on faculty consultations about individual teaching needs, as well as collaborate with staff to provide departmental consultation.

\section{Learning Communities}

In addition to facilitating large events, workshops, and individual consultations, our center's staff members coordinate instructor learning communities. These learning communities meet monthly throughout the academic year, and participants present their accomplishments at an annual breakfast that celebrates their work.

Our first-cycle intern became involved with our graduate teaching fellows learning community because the staff member who ran that program took an extended leave. The intern scheduled and attended all meetings, helped create agendas, independently facilitated several of the meetings, and consulted with learning community members as 
needed. Because the intern was involved in the community from the very beginning, participants reacted positively toward the shared facilitation in their end-of-year feedback.

Our second-cycle intern expressed an interest in working with our center's midcareer learning community in order to become familiar with services for experienced faculty. Because of the small size of the group (nine members, one of them a faculty facilitator), the staff agreed that it would be best for the intern to attend meetings as a participant rather than a facilitator so that the dynamic of the group's structure did not change. The community welcomed her participation in the discussions and expressed interest in her career development.

Since learning communities are very much participant driven, these experiences gave our interns the opportunity to observe and practice a diverse set of facilitation skills. The challenge in facilitating learning communities is often to provide guidance and boundaries while still allowing the group to set its own agenda and encourage discussion to evolve organically. In particular, the staff wanted each intern to observe the listening skills, flexibility, and ability to bring in resources that are necessary components of facilitating a faculty learning community.

\section{Teaching}

During the 2010 winter quarter, one of the consultants was revising a graduate course on college teaching, and the staff decided this would be an appropriate learning experience for the intern. In collaboration with the staff member teaching the course, the intern codesigned the syllabus, reading list, lesson plan, assessment activities, and course wiki system. In addition to team teaching with the staff member, the intern independently designed and taught two of the ten class sessions. Team teaching provided a unique professionalization experience for both the staff instructor and intern.

Because the teaching experience was such an intensive collaboration, there were effective opportunities for experimenting with team-teaching styles, developing rapport as cofacilitators, and learning from each other's pedagogical philosophies. The debriefing that followed each class session provided ample opportunity to discuss the rationales for and impact of instructional choices. Because neither the staff member nor the intern had cotaught before, both left the experience with an additional skill set that simultaneously offered personal fulfillment and professional value. 


\section{Teaching Center Administration}

During the first cycle (2007-2009) of our internship program, the intern was engaged in conversations about the administration of the unit and attended numerous staff meetings. However, because the first intern was quite clear in exit interviews that some of our decision-making processes remained opaque, the second intern was treated from the beginning as a full member of the core staff team. She attended almost all staff meetings, was given an annual review, and participated in our administrative decision-making discussions whenever and wherever appropriate. During the second cycle of the internship, for example, UCAT hired a visiting consultant, a new program coordinator, a new graduate associate, and several new graduate student facilitators for our university-wide teaching orientation. Our second intern was included in the review of applications and materials, the interview processes, and the hiring discussions for each of these positions.

Interns have also been given program coordination responsibilities, including our graduate interdisciplinary specialization in college and university teaching. In addition to collecting syllabi for courses in this program, interns responded to questions from interested graduate students and updated the program website with information as needed.

Finally, interns are given the opportunity to observe university committee meetings with the director of our center and other members of the staff. We have found that these committee shadowing opportunities allow the intern to learn more about the university's structure, the relationship between the teaching center and other administrative offices, and the kinds of administrative decisions to which teaching centers contribute.

\section{Professionalization Activities}

Each of our interns attended two POD conferences. In their first year, they traveled to the conference as an attendee to observe the presentations, network with other graduate students, and participate in the preconference workshop for new consultants in the field. In their second year, together with staff, interns prepare proposals on components of educational development.

Attending the annual POD conference also helps interns to experience the scholarship that is valued within the educational development community. Because our interns represent the interdisciplinarity of our field (thus far, one from education and the other from women's studies), attending a national conference allows them to see a variety of potential 
research projects. While other graduate students within our center may also participate in scholarly activities, their level of engagement in research is usually limited to supporting the staff's larger projects. Our interns, however, are encouraged to conduct research projects independently and in collaboration with staff and to submit their efforts for publication. In their initial training and as part of their more individualized research projects, both interns read widely within the field of educational development in order to contextualize their internship experience.

Our interns are also trained to develop technology skills that are becoming increasingly relevant to our field, such as Web design and the use of databases. In the second cycle of our mentorship program, our intern was trained on the design and implementation of wikis for interdisciplinary institutes in course and curriculum design, as well as wikis' use for structuring student learning experiences.

\section{The Benefits for Interns}

Throughout the two cycles of our mentorship program, based on feedback received through intern monthly reflection papers and exit interviews, we have found that the internship position meets at least four specific needs for graduate students interested in exploring educational development as a career.

\section{Hands-On Experience}

At the end of their two-year experience in our office, each intern was especially grateful for the opportunity to observe and have hands-on experience with workshops, consulting, large-event coordination, teaching, a variety of administrative tasks, and the facilitation of learning communities. Interns felt that the opportunities to talk through assessment practices of teaching centers, measure the effectiveness of services, and ask questions about their experiences before, during, and after they facilitated various activities were powerful components of their training.

\section{Mentoring and Debriefing}

Both interns appreciated being mentored by multiple staff members with different backgrounds, professional styles, and problem-solving approaches. The open conversations between interns and faculty members concerning instructional decisions, student engagement, and course planning were especially valuable to the first intern, who commented, 
"These conversations led to an appreciation of the multiple disciplines on campus, a grasp of students' experiences at a large research university, and an understanding of work-life challenges for faculty."

\section{A Contextualized Introduction to the Field}

Through the expectation that interns read widely within the field and begin to add to the research of educational development, they found that their work experience was contextualized in a variety of ways. Our first intern commented that she "appreciated the opportunities to frame teaching and learning in terms of student understanding. Considering the student experience from a university, program, and classroom perspective underscored the value of educational development as a growing field."

Our second intern, on returning from a job interview in the field, expressed her thanks that the internship exposed her to the underlying philosophies of practice in our center and of the field, including rationales for client confidentiality, the limitations of our center's mission, and the ethical obligations of consultants. Her awareness of these larger educational development concerns helped her more clearly articulate her personal philosophy of practice.

\section{Formalized Skill Building Through Intentional Training Activities}

Interns appreciated building their skills as educational developers through structured training rather than through self-teaching. From the beginning, staff envisioned a distinct sequence of planned activities that lead to a specified role in the organization and illustrate the complexities and challenges of work in educational development. Each intern learned that becoming a consultant involves building skills over time, recognizing one's strengths and weaknesses, and honing one's abilities to work with teaching center clients in a variety of environments.

\section{The Center Perspective}

After two cycles of this internship program, the UCAT staff have identified both benefits and challenges to mentoring graduate students into the field using this method.

\section{Benefits}

Perhaps the most obvious benefit to an internship program is having an extra staff member who, within a few months (depending on his or her background), can contribute to the center. After an introductory period, 
our interns handle basic, straightforward teaching center tasks (for example, small group instructional diagnoses and making short promotional presentations) as well as assist staff in tackling projects that frequently haunt staff to-do lists but fail to be accomplished due to work overload.

As consultants, we often hear our clients say that they are amazed at how much they learn from teaching, and the internship program has reinforced this statement. Having an intern on staff provided opportunities for reflection on our practice by stimulating conversations that may have occurred only because there was an intern in the center. Aspects of the mission of a teaching and learning center, such as confidentiality and the importance of voluntary client participation, are often embedded in daily practice but not explicitly discussed unless new staff are present. Discussing our center's mission and purpose on a regular basis as each new cycle of the internship program is initiated has led to many largerscale conversations about our center's strategic plan.

Having the intern shadow consultations has benefited both intern and consulting staff. Because consultation is so often done behind closed doors and under strict policies of confidentiality, it is all too often a skill that is developed in isolation. Just as we encourage instructors to open the classroom door and engage in a community of teachers, as consultants it is equally important to share and learn from one another. Although we frequently discuss the consultation process or specific consultations with colleagues, we have found that the presence of an intern creates an added structured opportunity for reflection and growth.

When discussing consultation with an intern, staff members are frequently required to articulate a rationale for decisions made about what to do and say (or not say). In some cases, intern questions have forced us to explore actions that have become so automatic that we are barely aware of them. In addition, debriefing after shadowed consults helps us think about other intervention options. Since the intern has shadowed several different consultants, she or he is often the link between different styles and approaches and can bring them into the conversation. Having a third person in the room gives a unique opportunity to hear another person's perspective on our words or actions and to see ourselves as our clients may see us. All of this helps us to become more self-aware and intentional in our practice.

\section{Challenges}

One administrative challenge was differentiating the internship position from other graduate associate positions. We learned that we had to clarify to staff and students that although both positions share job tasks, the 
intern is provided a wider range of experiences, is expected to take more of a leadership role in some of those tasks, and is simultaneously engaged in a study of the field. Those clarifications come at the start of employment for both interns and GAs, during staff meetings, and in individual meetings with GAs.

The other challenge we have encountered is the necessity of finding time to integrate, collaborate with, train, and supervise each intern. With any mentorship or training, time needs to be devoted to making sure the intern gains necessary skills and knowledge to be able to work independently. Monthly meetings with staff members; regular planning meetings about events, consultations, and other tasks; and impromptu discussions about the educational development field and job market all take time. Without these meetings and discussions, however, we have found that both the intern and the center staff can too easily lose focus or momentum and miss important learning opportunities. By organizing meeting times and delineating which staff will attend to specific discussions, we believe this challenge can be easily overcome.

\section{Conclusion}

We have found that the benefits of an internship program outweigh the challenges. However, because our internship program is still in its infancy, with only two interns having completed the program, our staff is just beginning to discuss formal mechanisms to measure the long-term success of this training and mentorship structure. Going forward, we plan to develop a set of measures of success for the internship structure that includes the following items:

- Regular staff review of interns. While interns are employed by our center, we ask that staff regularly review them through annual reports and throughout their participation in various events and training modules. These staff check-ins allow us to make sure each intern is receiving a wide range of experiences by working with several staff members.

- Exit interviews. Interviews with our former interns regarding their mentorship experience will assess a number of facets of the experience:

- Completeness. Do our interns believe that their training prepared them for what they are encountering in the field? Do any components of their training need more depth or breadth?

- Challenge. Are the interns challenged and intellectually stimulated by their work in our office? Are there areas where they would have liked to have received further training? 
- Support. Do we support our interns appropriately as potential new professionals as they train to enter a career track that may be different from what they originally planned? Is the field contextualized appropriately for interns as they prepare to find a job in educational development?

- Information regarding future employment. We will continue to track where our interns are employed after they leave our institution. Do they enter the field of educational development? What kind of position and at what level of skill are they hired?

- Longitudinal interviews. We plan to stay in touch with our interns in the long term so that we can see their progress and celebrate their accomplishments as colleagues. If our interns enter the community of educational developers, these interviews will probably be conducted regularly at POD gatherings.

Although we do not yet have long-term assessment data for our program, the initial feedback that we have gathered from both the interns and the staff with whom they have worked suggests value in the process. We believe that our doctoral internship program benefits the field of educational development as former interns enter the workforce. Intern exposure to guided reflection, the scholarship of teaching and learning, and the philosophies of educational development in advance of joining the field may allow smoother transitions into their positions as new professionals.

Based on our experience, we highly recommend that other teaching centers develop the opportunity to employ and mentor graduate student interns into the field of educational development. Our hope is that internship programs for graduate students will serve the field by creating a larger number of well-prepared new professionals. In the future, a comparison of outcomes from several internship systems may help us further determine the critical features of mentorship programs for new professionals.

\section{REFERENCES}

Chism, N.V.N. (2007, October). A professional priority: Preparing educational developers. Paper presented at the 32nd annual meeting of the Professional and Organizational Development Network in Higher Education, Pittsburgh, PA.

Gosling, D., McDonald, J., \& Stockley, D. (2007). We did it our way! Narratives of pathways to the profession of educational development. Educational Development, 8(4), 1-6.

Jensen, J. D. (2002). If I knew then what I know now: A first-year faculty consultant's top ten list. In K. H. Gillespie (Ed.), A guide to faculty 
development: Practical advice, examples, and resources (pp. 92-98). San Francisco, CA: Jossey-Bass.

Knapper, C. (2010). Plus ça change ... Educational development past and future. In J. McDonald \& D. Stockley (Eds.), New directions for teaching and learning: No. 122. Pathways to the profession of educational development (pp. 1-5). San Francisco, CA: Jossey-Bass.

McDonald, J. (2010). Charting pathways into the field of educational development. In J. McDonald \& D. Stockley (Eds.), New directions for teaching and learning: No. 122. Pathways to the profession of educational development (pp. 37-45). San Francisco, CA: Jossey-Bass.

McDonald, J., \& Stockley, D. (2008). Pathways to the profession of educational development: An international perspective. International Journal for Academic Development, 13(3), 213-218.

McDonald, J., \& Stockley, D. (2010). New directions for teaching and learning: No. 122. Pathways to the profession of educational development. San Francisco, CA: Jossey-Bass.

Meizlish, D. S., \& Wright, M. C. (2009). Preparing advocates for faculty development: Expanding the meaning of "growing our own." In L. B. Nilson \& J. E. Miller (Eds.), To improve the academy: Vol. 27. Resources for faculty, instructional, and organizational development (pp. 385-400). San Francisco, CA: Jossey-Bass.

Ouellett, M. L., \& Stanley, C. (2004). Fostering diversity in a faculty development organization. In C. Wehlburg \& S. Chadwick-Blossey (Eds.), To improve the academy: Vol. 22. Resources for faculty, instructional, and organizational development (pp. 206-225). San Francisco, CA: Jossey-Bass.

Stefani, L. (1999). On becoming an academic developer: A personal journey. International Journal for Academic Development, 4(2), 102-110.

Tierney, W. G., \& Rhoads, R. A. (1994). Faculty socialization as a cultural process: A mirror of institutional commitment (ASHE-ERIC Higher Education Report No. 93:6). Washington, DC: George Washington University, School of Education and Human Development. 